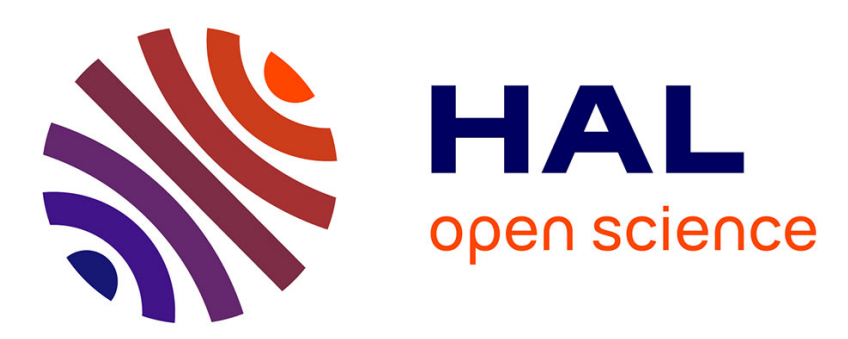

\title{
A neural-tree-based system for automatic location of earthquakes in Northeastern Italy
}

\author{
Stefania Gentili, Pier Luigi Bragado
}

\section{To cite this version:}

Stefania Gentili, Pier Luigi Bragado. A neural-tree-based system for automatic location of earthquakes in Northeastern Italy. Journal of Seismology, 2006, 10 (1), pp.73-89. 10.1007/s10950-005-9001-z . hal-00647262

\section{HAL Id: hal-00647262 \\ https://hal.inria.fr/hal-00647262}

Submitted on 1 Dec 2011

HAL is a multi-disciplinary open access archive for the deposit and dissemination of scientific research documents, whether they are published or not. The documents may come from teaching and research institutions in France or abroad, or from public or private research centers.
L'archive ouverte pluridisciplinaire HAL, est destinée au dépôt et à la diffusion de documents scientifiques de niveau recherche, publiés ou non, émanant des établissements d'enseignement et de recherche français ou étrangers, des laboratoires publics ou privés. 
J Seismol (2006) 10: 73-89 DOI: 10.1007/s10950-005-9001-z

The original publication is available at:

http://www.springerlink.com/content/0472505j50462614/

\title{
A neural-tree-based system for automatic location of earthquakes in Northeastern Italy ${ }^{1}$
}

\author{
S. Gentili, P. Bragato \\ Istituto Nazionale di Oceanografia e di Geofisica Sperimentale - OGS, \\ Dipartimento Centro Ricerche Sismologiche (CRSh), Via Treviso 55 - 33100 Udine, Italy
}

\begin{abstract}
A neural network system for $\mathrm{P}$ and S-picking and location of earthquakes in Northeastern Italy is described. It is applied to 7108 seismograms corresponding to 1147 earthquakes occurring in Northeastern Italy and surrounding area in the period 2000-2003. Its results are compared with two sets of manual picks and with the picks performed by the existing seismic alert system. The new system recognizes $89 \%$ and $67 \%$ of $\mathrm{P}$ and $\mathrm{S}$ arrival times, respectively, which allows locating $92 \%$ of the earthquakes. $\mathrm{P}$ and $\mathrm{S}$-picks differ from the best available manual picks by $0.00 \pm 0.07 \mathrm{~s}$
\end{abstract}

\footnotetext{
${ }^{1}$ This paper has not been submitted elsewhere in identical or similar form, nor will it be during the first three months after its submission to Journal of Seismology.
} 
$0.00 \pm 0.18 \mathrm{~s}$, respectively. The corresponding earthquake locations differ by $-0.18 \pm 0.77$ $\mathrm{km}$ in longitude, $0.10 \pm 0.62 \mathrm{~km}$ in latitude and $0.1 \pm 2.0 \mathrm{~km}$ in depth. These results suggest its use for alert purposes and rapid production of preliminary bulletins.

Considering a subset of picks that are common to all the available data sets, the absolute accuracy (i.e., the inverse of the standard deviation of differences between the estimated and the true, unknown arrival times) of each picking method is estimated. The best available manual data set has standard deviation $0.03 \mathrm{~s}$ for $\mathrm{P}$ waves and $0.07 \mathrm{~s}$ for $\mathrm{S}$ waves, while for the new system it is $0.06 \mathrm{~s}$ and $0.18 \mathrm{~s}$ for $\mathrm{P}$ and $\mathrm{S}$ waves, respectively.

Key words: absolute accuracy, automatic picking, earthquake location, Italy, neural tree.

\section{Introduction}

In recent years, there has been a great effort made to develop automatic systems for arrival time picking and earthquake location. Their application is mainly for alert purposes, in which case the response time is the key factor, or for the automatic processing of a large amount of data (e.g., for bulletin production). Many different approaches to automatic picking have been proposed: methods based on the comparison between the short- (STA) and the long-term average (LTA) of the signal (Earle and Shearer, 1987); autoregressive methods (Leonard and Kennett, 1999); algorithms that analyze wave-polarization (Cichowicz, 1993); algorithms that adopt the wavelet transform (Zhang et al., 2003); algorithms that use neural networks (among the others, Dai and MacBeth, 1997; Wang and Teng, 1997; Zhao and Takano, 1999). Neural networks have the advantage that they adopt data-driven learning schemes to find the 
solution to the problem. Therefore, it is not necessary to have a deep knowledge of the problem to obtain a solution, which can be found even if the input information is redundant or noisy.

In this paper we propose a neural network system named TAPNEI (Time Arrival Picker for NorthEastern Italy) for the automating picking of seismograms from the Short-period Seismometric Network of Northeastern Italy (Figure 1). It is an evolution of TAP (Time Arrival Picker) by Gentili and Michelini (2005). TAP was developed and tested for the off-line processing of some 5,000 seismograms corresponding to 342 earthquakes of the 1997 Umbria-Marche sequence (Central Italy). These earthquakes are clustered in space, have quite similar focal mechanisms and were recorded by a small aperture network (about $30 \mathrm{~km}$ radius) surrounding them. TAPNEI is intended for on-line processing of data in a wider area, so that the characteristics of the earthquakes, the position of the stations relative to the sources and site conditions are extremely variable. Unlike TAP, earthquakes external to the network are also considered (up to about $120 \mathrm{~km}$ from the nearest station). Noticeably, stations in Northeastern Italy are characterized by some degree of horizontal polarization of $\mathrm{P}$ waves, not observed in Central Italy, that makes recognizing S arrivals more difficult.

The improvements introduced with respect to TAP concern:

1. the implementation of a technique to distinguish earthquakes from noise recordings (other seismic sources, like explosions, are not considered in this work). This step was not required for TAP because seismograms were preselected by visual inspection. TAPNEI analyzes portions of signals selected by the field digitizer based on an STA/LTA algorithm; 
2. the redefinition and tuning of some of the signal features analyzed by the neural network;

3. the use of a different neural network architecture for S phase picking;

4. the application of automatic picking also to single component, vertical stations (in Central Italy all the stations were 3D);

5. the definition of a weighting schema for the picks to use for earthquake location. In the following, we describe the Short-period Seismometric Network of Northeastern Italy and furnish some basic elements of neural networks. Then, we describe TAPNEI in detail. We evaluate its performance for a database composed of over 7,000 traces corresponding to 1147 events occurring in Northeastern Italy and the surrounding area during the years 2000-2003. The automatic picks and the corresponding earthquake locations are compared with those performed manually for bulletin production and tomographic studies and with those performed by the automatic alert system currently in use in Northeastern Italy. This analysis estimates the accuracy of our method relative to the others. We also discuss a technique to estimate the absolute accuracy of each of the available sets of picks (manual and automatic).

\section{The Short-period Seismometric Network of Northeastern} Italy and the FAAS alert system

The Short-period Seismometric Network of Northeastern Italy (NEI seismometric network, Priolo et al., 2005) is operated by the Centro di Ricerche Sismologiche (CRS), a Department located in Udine of the Istituto Nazionale di Oceanografia e di Geofisica Sperimentale (OGS). Established in 1977 with a few stations in the epicentral area of the 1976 Friuli earthquake (ML 6.4), it monitors the 
region between Lake Garda on west and the Italian/Slovenian border on east as well as a limited portion of western Slovenia and southern Austria (Figure 1). At present, the network consists of 21 stations: 17 are equipped with a 1-Hz three-component Lennartz LE-3D seismometer; one with a Mark L4C 1-Hz vertical seismometer installed in a 100 meter deep borehole; two have a velocimetric/accelerometric couple (BAD and BOO); one (UDI) is equipped with a Guralp CMG-5T accelerometer and is not considered for automatic picking. All the stations have a MARS88 data logger and acquire at either 62.5 or 125 samples per second with an anti-alias filter at $25 \mathrm{~Hz}$ or $50 \mathrm{~Hz}$, respectively. An STA/LTA algorithm is used to recognize candidate earthquakes. The corresponding data are acquired on a workstation at the central station in Udine using the Lennartz MARS88/RC acquisition system. The data is transmitted by UHF radio. The stations share 7 frequencies based on a token-passing mechanism. Due to the bandwidth limitation, acquisition is three-component for 16 stations, while 5 stations have only vertical recording enabled.

The Friuli Automatic Alert System (FAAS; Bragato and Govoni, 2000) has been active at CRS since 1996. It starts processing if a coincidence arises among at least 4 stations. It recognizes local earthquakes based on the frequency content of the seismograms, performs $\mathrm{P}$ and $\mathrm{S}$ picking, locates the earthquakes and estimates their magnitudes. In particular, for P-picking FAAS uses the algorithm by Baer and Kradolfer (1987) while for S-picking it adopts the solution by Bragato and Govoni (2000). Based on the location and the magnitude of the earthquake, FAAS establishes the level of alert and the users (civil protection authorities and seismological institutions) to notify of earthquake arrivals by fax, e-mail or short messages to cellular 
phones. Automatic locations are also reported on the CRS web page (http://www.crs.inogs.it).

\section{Artificial Neural Networks}

The theory of Artificial Neural Networks (ANN) and their application to seismic phase classification is discussed in detail by Dowla et al. (1990). Here we summarize some basic elements from their tutorial paper.

An ANN is a processing system that takes in input a vector $\mathbf{x}=\left(x_{1}, x_{2}, \ldots, x_{N}\right)$ and computes the corresponding output vector $\mathbf{y}=\left(y_{1}, y_{2}, \ldots, y_{M}\right)$. Vector $\mathbf{x}$ is classified into class $\bar{i}$ if $y_{\bar{i}}>y_{i}$ for $i \neq \bar{i}$. Internally, an ANN is consists of a number of interconnected nodes called the neurons. Each neuron has L inputs and one output. Input values come from other neurons (possibly including the neuron itself) or coincide with some of the inputs to the ANN. The neuron weights and sums its input values to form the intermediate scalar $s: s=\sum_{i=1}^{L} w_{i} \cdot x_{i}$. Then it computes its output as a nonlinear function of $s$. In this paper we consider the sigmoid function $f(s)=\frac{1}{1+e^{-\beta s}}$ where $\beta$ is a constant.

The neurons can be interconnected in an arbitrary way. The simplest ANN is the perceptron (Figure 2a), with neurons partitioned in an input layer and an output layer. The more used architecture is the multi-layered feedforward network or multilayer prerceptron (MLP), shown in Figure 2b. In an MLP, neurons are organized in an input layer, an output layer and a number of hidden layers. Each neuron in a layer furnishes 
its output to the neurons in the subsequent layer: there are no feedbacks or lateral connection in a layer.

When the architecture is selected, suitable weights must be defined in order to get the ANN to solve a particular classification problem. This is done automatically in the learning phase. Given a training set, consisting of a number of input vectors $\left(\mathbf{x}_{1}, \mathbf{x}_{2}, \ldots ., \mathbf{x}_{T}\right)$ and the corresponding target (or desired) output vectors $\left(\mathbf{y}_{1}, \mathbf{y}_{2}, \ldots ., \mathbf{y}_{T}\right)$, the weights are chosen to minimize the error function:

$$
\sum_{i=1}^{T}\left|\mathbf{y}_{i}-\mathbf{y}_{N N i}(\mathbf{w})\right|^{2}
$$

where $\left(\mathbf{y}_{N N 1}(\mathbf{w}), \mathbf{y}_{N N 2}(\mathbf{w}), \ldots ., \mathbf{y}_{N N T}(\mathbf{w})\right)$ is the set of output vectors generated by the network for the set of weights w. For an MLP, the function can be minimized by means of the backpropagation algorithm, whose validity was demonstrated by Dowla et al. (1990). The application of the ANN to new patterns not used in the learning phase is called its "generalization".

The choice of the network architecture is critical. For example, it has been shown that a perceptron can only solve classification problems that are linearly separable (i.e., only when the classes can be separated by hyperplanes in $\mathfrak{R}^{N}$ ). Often the choice is left to the programmer, who compares the performances of a limited number of alternative networks. In this work we have used the formalism IUANT2 (Gentili, 2003a; Gentili, 2003b), which automatically selects the best architecture in the learning phase. The resulting network consists of a tree where each node is a simple perceptron (Figure 3).

Similarly to TAP, TAPNEI uses two distinct neural networks for $\mathrm{P}$ and $\mathrm{S}$ picking, respectively. In Central Italy, a simple perceptron was sufficient in both cases. 
For TAPNEI we have found that $\mathrm{S}$ picking requires two perceptrons (Figure 3). This result demonstrates that $\mathrm{S}$ picking in Northeastern Italy is a more complex task. The classification problem is not simply linearly separable. The perceptron on the top of Figure 3 performs a first classification and recognizes a subset of $\mathrm{S}$ picks. The remaining cases are analyzed by the second perceptron that performs a further linear separation between picks and not picks.

\section{The TAPNEI system}

TAPNEI works on three-component seismograms with mean removed (the treatment of single-component, vertical seismograms is described later) that the field data loggers have recognized as candidate earthquakes using the STA/LTA algorithm. Much of the analysis is performed using three basic statistical measures (variance, absolute value of skewness and kurtosis) computed for the entire signal or portions of it:

$$
\begin{array}{r}
\operatorname{Var}=\sigma^{2}=\frac{1}{N+1} \sum_{i=1}^{N}(x-\bar{x})^{2}, \quad \text { Skew }=\left|\frac{1}{N+1} \sum_{i=1}^{N}\left(\frac{x_{i}-\bar{x}}{\sigma}\right)^{3}\right|, \\
\operatorname{Kurt}=\frac{1}{N+1} \sum_{i=1}^{N}\left(\frac{x_{i}-\bar{x}}{\sigma}\right)^{4}-3
\end{array}
$$

where $\bar{x}$ denotes the mean of the signal. This choice was suggested by the fact that the $\mathrm{P}$ wave arrival perturbs the distribution of the signal that, for background seismic noise, is almost normal. When $\mathrm{P}$ waves arrive, the amplitude of the oscillation increases and a larger value of variance results. The skewness is a measure of the asymmetry of the distribution. It has a peak around the onset pick-point, because there is much more energy on the right of the pick-point than on its left. The kurtosis is a non-dimensional quantity that measures the relative peakedness or flatness of the distribution relative to a 
normal distribution. When the sliding window border reaches the onset pick-time, the kurtosis has a positive peak due to the asymmetry of the distribution. This feature is often more noisy than the skewness. These facts are still valid to some degree for $\mathrm{S}$ waves, though they emerge from the coda of $\mathrm{P}$ waves.

Preliminary tests have also shown that the rapidity of change of the previous features contributes to identifying wave arrivals better. Then, we also considered a combination of skewness and kurtosis and their derivatives with respect to time we call Integ (Integrated-Information):

$$
\text { Integ }=\text { Skew } \cdot \operatorname{Kurt}\left|\frac{d(\text { Skew })}{d t} \cdot \frac{d(\text { Kurt })}{d t}\right|
$$

\subsection{Trace selection}

In the first step, TAPNEI discards pure noise traces. They are recognized based on the low value of the kurtosis computed for the entire seismogram. It is close to 0 even if some spikes are present. The remaining traces are considered for $\mathrm{P}$ and $\mathrm{S}$ picking. For this purpose, the two horizontal components are reduced to a single component according to $h_{i}=\sqrt{n_{i}^{2}+e_{i}^{2}}$.

\section{2. $P$ picking}

For P-picking, the seismograms are high-pass filtered at $2 \mathrm{~Hz}$. For each sample of both the vertical and the horizontal component the four features in equations (2) and (3) are computed using a 2.048 s long sliding window (i.e. 128 and 256 samples for traces sampled at 62.5 and 125 samples per second, respectively) centered on the sample itself. The resulting 8 time series $\left(\right.$ HVar $_{i}$, Var $_{i}$, HSkew $_{i}$, VSkew $_{i}$, etc., where $H$ 
stands for horizontal and $V$ for vertical) are normalized between 0 and 1 before their use. The first sample $\bar{i}$ at which $V$ Var ${ }_{i}$ exceeds a given threshold is considered a rough estimation of the $\mathrm{P}$ arrival time.

A neural network is used to search for a more refined estimation in the interval $(\bar{i}-M, \bar{k})$, where $M$ is fixed and $\bar{k}$ is the point of maximum for $\operatorname{HVar}_{i}$, which is assumed to follow the $\mathrm{S}$ arrival time. To classify the candidate sample $i_{C} \in(\bar{i}-M, \bar{k})$ as either pick or not pick, the network considers a sequence of 21 samples centered on $i_{C}$ for each of the five features VVar, VSkew, VKurt, VInteg and HVar. It takes in input the vector (pattern) of 105 elements

$$
\begin{aligned}
& \left(\text { Var }_{i_{c}-10}, \ldots, \text { Var }_{i_{c}+10}, \text { VSkew }_{i_{c}-10}, \ldots, \text { VSkew }_{i_{c}+10}, \text { VKurt }_{i_{c}-10}, \ldots, \text { VKurt }_{i_{c}+10},\right. \\
& \text { VInteg } \left._{i_{c}-10}, \ldots, \text { VInteg }_{i_{c}+10}, \text { HVar }_{i_{c}-10}, \ldots, \text { HVar }_{i_{c}+10}\right)
\end{aligned}
$$

It supplies an output in the range $[0,1]$. The candidate sample with highest output is selected as the neural network (NN) pick. The network has been built and trained according to the IUANT2 formalism using 81 such patterns, 60 of which correspond to time windows centered on the manual picking of $\mathrm{P}$ waves (G. Bressan, personal communication, 2004) and 21 correspond to other regions of the seismogram. As anticipated in the Introduction, the resulting neural tree is a simple perceptron (Figure 2a).

As the final estimation of the $\mathrm{P}$ arrival time, TAPNEI provides the NN pick, if it differs from the rough pick by less than $0.12 \mathrm{~s}$, otherwise the rough pick. The threshold $0.12 \mathrm{~s}$, as other similar thresholds introduced later for the $\mathrm{S}$ picking, has been chosen empirically, in order to reduce the dispersion of automatic $\mathrm{P}$ picks relative to the corresponding manual picks. 


\subsection{S picking}

To perform S-picking, seismograms are band-pass filtered between 2 and $8 \mathrm{~Hz}$. The signal features are built as for P-picking. Two more features are considered:

1. The feature called "Varrot" (i.e., variance under rotation).

$$
\text { Varrot }=\frac{1}{18 \cdot N-1} \sum_{\theta=0,10,}^{170} \sum_{i=1}^{N}\left(p_{i \theta}-\bar{p}\right)^{2}
$$

where $p_{i \theta}$ is the projection for a single sample $\left(p_{i \theta}=n_{i} \cos (\theta)+e_{i} \sin (\theta)\right)$ and $\bar{p}$ is the mean value of $p_{i \theta}$ with 18 different rotations of 10 degrees. This feature exploits the fact that S-waves have nearly horizontal polarization;

2. a feature that exploits the fact that $\mathrm{S}$ waves have longer period and larger amplitude than P-waves, and then, higher area in a semiperiod of the seismogram. The feature is derived from that introduced by Bragato and Govoni (2000). They compute their feature separately for the two horizontal components. In TAP the two components are combined using $p_{i \theta_{M A X}}$, the projection of the point $\left(n_{i}, e_{i}\right)$ along the direction of maximum polarization of the signal $\theta_{\text {MAX }}$. The feature adopted for TAP is:

$$
\operatorname{FeatBG}(i)=\sum_{k=z_{j}}^{z_{j+1}-1}\left|p_{k \theta_{M A X}}\right| \quad \forall i \in\left[z_{j}, z_{j+1}\right)
$$

where $z_{j}$ are the zero-crossing points for $p_{k \theta_{M A X}}$. For TAPNEI we found that better results are obtained with a smoothed version of FeatBG :

$$
\text { FeatBG } 2(i)=\frac{1}{2 L+1} \sum_{j=i-L}^{i+L} \text { FeatBG }(j)
$$


For TAP, the feature Varrot was used for a rough estimation of the $\mathrm{S}$ arrival time, simply choosing the sample at which the features exceeds a given threshold. This technique has been demonstrated to be unreliable in Northeastern Italy because many seismograms are characterized by some degree of horizontal polarization of $\mathrm{P}$ waves. The problem is illustrated in Figure 4. If the polarization of $\mathrm{P}$ waves is negligible (Figure 4a), after the $\mathrm{S}$ arrival the feature Varrot (thick line) quickly reaches values that are much higher than those assumed on $\mathrm{P}$ waves. If the polarization of $\mathrm{P}$ waves is significant (Figure 4b), the $\mathrm{S}$ arrival is not detectable using a threshold because Varrot has higher values on $\mathrm{P}$ waves than at the beginning of $\mathrm{S}$ waves. TAPNEI assumes that the rough S pick (denoted $S V$ ) corresponds to the first "significant" local minimum encountered when analyzing the feature Varrot from right to left. For this purpose, the feature Varrot is convolved with the derivative of a Gaussian using an 11 samples long sliding window and $\sigma=3$ samples. It furnishes a sort of smooth derivative of the signal, we call DVarrot (thin line in Figure 4). A "significant" local minimum is found if

1. DVarrot changes sign (i.e. it crosses the zero axis);

2. Varrot is under the threshold 0.3 .

The rough $\mathrm{S}$ pick $S V$ is discarded if it is too close to the estimated $\mathrm{P}$ pick (i.e., they differ by less than $0.4 \mathrm{~s}$ ). Also the feature FeatBG2 is processed in a similar way to obtain a second rough $S$ pick, denoted $S F$. The introduction of $S F$ is new, and aims to increase the probability of having at least one preliminary estimation of the $\mathrm{S}$ arrival time.

If either $S V$ or $S F$ has been found, Varrot and FeatBG2 are sent, together with the horizontal variance, skewness, kurtosis and Integ (equations (2) and (3)), to another IUANT2 neural tree, trained to recognize S-phase picking times $(S N N)$. This neural tree 
was trained using 139 patterns of which 83 corresponding to time windows centered on the S-wave picking time and 56 corresponding to other regions of the seismogram. The resulting neural tree consists of two perceptrons (Figure 3) and has three outputs (rectangles in Figure 3). These outputs are combined according to the IUANT2 formalism to provide a unique output value in the range $[0,1]$, we call the "neural tree output". The sequence of neural tree outputs (one for each sample in the interval between the P pick and the point of maximum for $\mathrm{HVar}_{i}$ ) is analyzed to recognize the $\mathrm{S}$ onset time. The final pick is one of the following (in this order, if available):

1. the sample corresponding to the maximum in the sequence of the neural tree outputs, if compatible with $S V$ (i.e., differing by less than 0.42 s) or $S F$;

2. the sample corresponding to the first local maximum in the sequence of the neural tree outputs that is compatible with $S V$ or, if not available, $S F$;

3. $S V$;

4. $S F$.

\subsection{Picking of single-component, vertical signals}

In order not to lose the picks from single-channel stations, in this case TAPNEI simulates the horizontal components by copying the only available vertical ones. This affects the performance of the method. In particular, the Varrot feature can not show the point where horizontal polarization starts. However, it highlights the increase of amplitude of the signal due to the arrival of $S$ waves. The other features also behave similarly. We have found that the neural system is still able to furnish acceptable $\mathrm{P}$ and S picks, useful for better constraining the earthquake location (the results are discussed in the following). 


\subsection{Tuning the system}

Picks are performed in the feature space. We remind that the two neural networks used for $\mathrm{P}$ and $\mathrm{S}$ picking are trained to recognize a phase arrival that occurs in the middle of the sliding window used to compute the features $(2.048 \mathrm{~s}$ long). Then, theoretically, a pick in the feature space should anticipate by $1.024 \mathrm{~s}$ the true arrival time. A comparison between manual and automatic picks has shown that the time shift is different and a further correction is required. For stations with at least 100 traces, we apply a time correction equal to the mean difference between automatic and manual pickings for that station. For the other stations, we apply a time correction equal to the mean difference between automatic and manual pickings computed for the entire network.

\subsection{Weighting criterion}

For earthquake location, TAP ranks the final pickings in two classes: high quality, if the NN pick is selected, or low quality, if they correspond to the rough estimation. TAPNEI introduces a ranking of the picks following the 5 classes adopted by HYPO71 (from 0, for very good picks, to 4, corresponding to very inaccurate picks, not considered for earthquake location) based on the signal-to-noise ratio (S/N) computed in the surrounding of the picking point. The weighting criterion is summarized in Table 1. In particular, $\mathrm{S} / \mathrm{N}$ is defined as the ratio between the mean absolute value of the amplitude after and before the onset time using two windows $1 \mathrm{~s}$ long (for $\mathrm{S}$ waves the noise corresponds to the coda of $\mathrm{P}$ waves). This choice has been demonstrated to be more robust than that of Scherbaum and Johnson (1992), who use 
the ratio between the maximum of the signal amplitude and the maximum of the noise amplitude.

\section{Application}

TAPNEI has been applied to a set of 7108 seismic recordings corresponding to 1147 earthquakes with duration magnitude MD in the range 0.6-5.6detected by the NEI seismometric network in the years 2000-2003. For comparison, three different databases of manual and automatic picks for the same traces have been considered:

1. arrival times from the bulletin of the NEI network (OGS, 2000-2003) (OGS database);

2. a less complete but more accurate database of the $\mathrm{P}$ and $\mathrm{S}$ arrival times produced for tomography applications (G. Bressan, personal communication, 2004) (GB database);

3. arrival times picked by the existing Friuli Automatic Alert System (FAAS database).

For each database, all the events with at least 4 arrival times have been located using HYPO71 (Lee and Lahr, 1975) with the same velocity model and control parameters adopted for the bulletin of the network. The percentage of available picks and earthquake locations available for TAPNEI and the three reference databases are shown in Figure 5. The reported values reflect different picking capabilities and choices. The OGS database is the most complete: for bulletin production, the operators try to pick as much as possible. Even low quality picks are considered, possibly with HYPO71 quality 4 (e.g., the missing 2\% of P-picks in Figure 5). Only 3\% of the earthquakes are not located due to the low quality of the data or to the small number of 
stations involved. Reliability is the key point for the FAAS alert system. It often discards low quality picks that could compromise the location of the earthquakes. The criteria for the GB database are even more selective. Seismic tomography requires earthquakes with many good quality recordings and hypocenters that are optimally distributed relatively to the area under analysis and to the available stations. TAPNEI performs much better than FAAS: it picks $18 \%$ more $\mathrm{P}$ phases, $36 \%$ more $\mathrm{S}$ phases and locates $30 \%$ more earthquakes. The percentage of located earthquakes is very close to that of the OGS database (92\% vs. 97\%). For all the databases, $\mathrm{P}$ picking is a prerequisite for S picking. TAPNEI produces valid S picks for $75 \%$ of traces with the $\mathrm{P}$ phase picked. This percentage is identical to that of the OGS database (it is $84 \%$ for GB and $44 \%$ for FAAS).

The capabilities of TAPNEI have also been assessed by analyzing the distribution of the differences $\Delta \mathrm{P}$ and $\Delta \mathrm{S}$ with the corresponding arrival times in the manual databases (GB and OGS). The mean $\mu_{\mathrm{t}}$ and the standard deviation $\sigma_{\mathrm{t}}$ of the distributions are presented in Table 2. The mean is a measure of the systematic error, while the standard deviation provides a measure of the accuracy of the proposed method. In particular, we define the accuracy in the following way:

$$
\text { Accuracy }=\frac{1}{\sigma_{t}}
$$

Performance in terms of $\mu_{\mathrm{t}}$ and $\sigma_{\mathrm{t}}$ is similar for the two databases. The greatest difference is for $\mu_{\mathrm{t}}$ for $\mathrm{S}$ waves. It is important to note that the values presented in Table 2 are also affected by the manual picking error. So, the true standard deviation of TAPNEI (that related to the true, unknown arrival times) could be smaller than the $\sigma_{\mathrm{t}}$ values of Table 2. Furthermore, the difference between the two $\mu_{\mathrm{t}}$ for $\mathrm{S}$ waves could 
mean that at least one of the manual datasets is affected by a small systematic error. The values of $\sigma_{\mathrm{t}}$ for $\mathrm{S}$ waves in Table 2 have been computed considering $\mathrm{S}$ picks estimated on both three-component and vertical recordings. Such accuracy remains unchanged if computed for three-component stations. It decreases slightly $\left(\sigma_{t}\right.$ increases from 0.18 to 0.21 in the comparison with GB) for vertical stations. The moderate variation testifies to the good quality of such pickings. Some examples of three-component seismograms with the corresponding GB and TAPNEI picks are shown in the Figures from 6 to 10. They are sorted according to the increasing value of the differences between the manual and the automatic S pick.

Similarly to Gentili and Michelini (2005), we have used the two parameters Recall and Precision to evaluate the capability of the system to detect the onset of seismic waves and to reject false alarms, respectively. The two parameters are defined as follows (Aviles-Cruz et al, 1995):

$$
\begin{aligned}
& \text { Re call }=\frac{t}{T} \\
& \text { Precision }=\frac{t}{t+f}
\end{aligned}
$$

where $T$ is the number of picks in the manual database, while $t$ and $f$ are the number of true and false picks produced by TAPNEI for the same set of $T$ seismograms. In this analysis the false picks are those recognized as outliers for the normal distribution $\mathrm{N}\left(\mu_{\mathrm{t}}, \sigma_{\mathrm{t}}\right)$ using the Chauvenet data rejection method (Taylor, 1982). For a normal distribution $\mathrm{N}(\mu, \sigma)$, the probability to observe a value that differs from the mean $\mu$ for more than a quantity $\delta$ is:

$$
\operatorname{Prob}(|X-\mu|>\delta)=2 \cdot[1-F(\mu+\delta)]
$$


where $\mathrm{F}$ is the cumulative density function (cdf) of $\mathrm{N}(\mu, \sigma)$. Given a set of $\mathrm{M}$ observations, the expected number of data that differ from $\mu$ for more than $\delta$ is

$$
K=M \cdot \operatorname{Pr} o b(|X-\mu|>\delta)
$$

The data rejection method fixes $\delta$ so that $\mathrm{K}=1 / 2$, and recognizes as the outliers the data that differs from $\mu$ for more than $\delta$.

Precision and Recall computed for TAPNEI in respect to GB and OGS are reported in Table 2. The Precision ranges from 0.90 in the comparison of $\mathrm{P}$ picks with OGS data to 0.98 in the comparison of $\mathrm{S}$ picks with GB data. The most significant values of Recall are those for the OGS data set, which is the most complete: the values for P picks and S picks are similar (0.80 and 0.76 , respectively).

The same analysis has been performed for the picks of the FAAS alert system. By comparing the results in Table 2, one can see that TAPNEI performs better than FAAS for systematic error and accuracy, with the exception of $\sigma_{t}$ of $\mathrm{P}$ picking, which is quite similar for the two methods. In all the cases, FAAS has much lower Recall and higher or equal Precision. This means that FAAS is more conservative and ensures less false picks at the cost of discarding or not detecting a large quantity of arrival times.

Table 3 presents the differences in $\mathrm{km}$ between the hypocentral coordinates estimated using TAPNEI arrival times and those picked manually (GB and OGS databases). Such differences derive from those of the estimated arrival times but also from those of the weighting criteria. In both cases $\sigma$ is lower than $1 \mathrm{~km}$ for the estimation of longitude and latitude, while it is about $2 \mathrm{~km}$ for depth. The comparison with GB shows moderate systematic errors for all the three coordinates. In the comparison with OGS, all the systematic error is concentrated in a more significant 
difference of depth. Table 3 also shows the analogous information for FAAS locations. FAAS performs worse, especially for depth determination.

\section{Absolute estimations of accuracy of automatic and manual picks}

Thus far, we have considered the relative accuracy of TAPNEI and FAAS picks with respect to the manual ones. Under the hypothesis that the picks of the 4 databases are independent, it is also possible to estimate the absolute accuracy of each method. Since the variance of two independent random variables is additive (Press et al. 1992), the variance $v_{i j}$ on the difference of the picks of two databases $i$ and $j$ can be expressed in the following way:

$$
v_{i j}=v_{i}+v_{j}
$$

where $v_{i}$ is the variance of the distribution of the differences of the $i$-th database with the real (unknown) picks and $v_{j}$ the variance of the distribution of the differences of the $j$-th database with the real (unknown) picks. For each type of pick (P or $\mathrm{S}$ ) there are 6 different values of $v_{i j}$ obtained by combining the four $v_{i}$ two-by-two according to the matrix product

$$
\mathbf{A} \cdot \mathbf{v}=\mathbf{v}_{\Delta}, \quad \text { where } \quad \mathbf{A}=\left[\begin{array}{cccc}
1 & 1 & 0 & 0 \\
1 & 0 & 1 & 0 \\
1 & 0 & 0 & 1 \\
0 & 1 & 1 & 0 \\
0 & 1 & 0 & 1 \\
0 & 0 & 1 & 1
\end{array}\right], \quad \mathbf{v}=\left[\begin{array}{c}
v_{1} \\
v_{2} \\
v_{3} \\
v_{4}
\end{array}\right] \text { and } \mathbf{v}_{\Delta}=\left[\begin{array}{c}
v_{12} \\
v_{13} \\
v_{14} \\
v_{23} \\
v_{24} \\
v_{34}
\end{array}\right]
$$

It is an overdetermined linear system involving the four unknowns $v_{i}$ and six equations. In general, it doesn't admit an exact solution. The best approximate solution 
in the least-square sense can be found using singular value decomposition (Press et al. 1992). It corresponds to the vector $\mathbf{v}$ that minimizes $\left|\mathbf{A v}-\mathbf{v}_{\Delta}\right|^{2}$. We have performed this analysis separately for $\mathrm{P}$ and $\mathrm{S}$ phases and the results are shown in Table 4. To ensure coherency among different $v_{i j}$, they have been computed considering the intersection of the four databases (363 seismograms with both $\mathrm{P}$ and $\mathrm{S}$ picks in all the four databases). In general, these are good quality signals, characterized by high $\mathrm{S} / \mathrm{N}$ ratio. So, it is likely that the accuracy in Table 4 overestimates the accuracy of the entire database.

From Table 4, it is possible to see that, for TAPNEI, the absolute accuracy is similar to the relative one presented in Table 2. The standard deviation is about twice than that of the best manual database (GB), while, for the subset of high quality traces considered here, it is identical to that of FAAS. The analysis shows that the two sets of manual picks (GB and OGS) have the same accuracy for P picks, while the GB database has higher quality $\mathrm{S}$ picks.

With the same technique it has been obtained the absolute accuracy of longitude, latitude and depth estimated with the four data sets. The results are presented in Table 4. TAPNEI allows localization whose accuracy is very similar to that of the manual databases, at least for latitude and longitude. Moreover, the localization is slightly more accurate than that by FAAS. It is important to note that the results can be influenced by the velocity model adopted, and therefore the real accuracy could be different. Considering that the accuracy of the picks is similar, the large difference in location accuracy between the GB and OGS databases could be due to the better estimate of the weights in the GB database. 


\section{Conclusions}

We have developed an automatic location system based on neural networks to apply in Northeastern Italy. Compared with the analogous automatic system currently in use for alert purposes, the new system:

- significantly increases the percentage of picked arrival times and located earthquakes (Figure 5);

- furnishes arrival times that are closer to those obtained by human operators (Table 2). It reduces or eliminates systematic errors and, for $\mathrm{S}$ picking, increases the accuracy. In particular, for the larger data set that coincides with the OGS bulletin, the standard deviation of the difference between manual and automatic S-picks decreases from $0.25 \mathrm{~s}$ to $0.18 \mathrm{~s}$. This significantly improves the estimation of the hypocentral depth (Tables 3). For both the automatic systems the epicentral coordinates differ from those obtained from manual data by about $1 \mathrm{~km}$;

- TAPNEI and FAAS perform similarly for the good quality signals used in the previous section for the analysis of the absolute accuracy of picking.

These elements lead to the conclusion that the two system are almost equivalent for standard alert purposes, when the main interest is for the epicentral coordinates of strong earthquakes. In this case, good quality recordings are available and a location error on the order of $1 \mathrm{~km}$ is acceptable. The higher sensitivity and accuracy of TAPNEI could be better exploited for the run-time analysis of seismic sequences, aimed at delimiting the fault area and forecasting their possible evolution. Good quality automatic locations of weak earthquakes could also help in designing a temporary network to be deployed in the epicentral area, similarly to Hardt and Scherbaum (1994). 
The characteristics outlined also make TAPNEI a valid tool for preliminary bulletin production. In tomographic studies, its results could be used for a preliminary analysis aimed at recognizing the earthquakes of interest and selecting the data to revise manually.

Both TAPNEI and FAAS are unable to distinguish between earthquakes and explosions. Blasts in the monitored area are related to quarry activity, military training in firing grounds, geophysical prospection and firing of unexploded bombs found on the land and on the sea. The time and the approximated location of the latter events are commonly announced in advance by military and civil protection authorities. For the time period 2000-2003, the OGS bulletin reports 68 events that are classified as possible explosions. Much of them (66) are weak events recorded by one or two stations. Only the firing of two unexploded bombs in the Gulf of Trieste (Northern Adriatic Sea) triggered more than two stations and made the source location with manual picks feasible. The strongest of them (estimated magnitude MD 2.8) has been processed by both TAPNEI and FAAS. Though unable to recognize the type of source, the two automatic systems have furnished arrival times in good agreement with those obtained by the seismologists.

The analysis of absolute accuracy of manual and automatic picking has been conducted on a subset of good quality signals under the hypothesis of independence between the readings in the four databases. It confirms that the quality of automatic picks is still lower than that of manual picks (by about a factor 2 for both $\mathrm{P}$ and $\mathrm{S}$ picking). Concerning manual picking, OGS and GB are equivalent for $\mathrm{P}$ waves, while the GB revision significantly improves the estimation of $S$ arrival times. The analysis also quantifies by how much $\mathrm{S}$ picking is a more difficult task than $\mathrm{P}$ picking: for all the 
databases we estimate that $\mathrm{P}$ picking is at least twice as accurate than $\mathrm{S}$ picking. Furthermore, the accuracy of $\mathrm{P}$ picks in both the manual databases is very near to its upper limit, dictated by the sampling rate. In fact, $0.03 \mathrm{~s}$ (Table 4) corresponds to about 2 samples for the majority of stations of the NEI seismometric network (19 out of 21) that are sampled at 62.5 samples per second (0.016 s sampling period).

\section{Acknowledgements}

We would like to thank Gianni Bressan, Marcello Candido, Adriano Snidarcig and Sandro Urban for the manual picking of the seismograms of the NEI seismometric network. We would also like to thank Aladino Govoni for his valuable discussions and suggestions. We are grateful to two anonymous reviewers for their fruitful comments.

\section{References}

Aviles-Cruz, C., Guèrin-Duguè, A., Voz, J.L. and Van Cappel, D., 1995, Deliverable R3-B1-P Task B1: Databases ELENA-NERVES-2 "Enhanced Learning for Evolutive Neural Architecture”, ESPRIT -Basic Research Project Number 6891.

Baer, M. and Kradolfer, U., 1987, An automatic phase picker for local and teleseismic events, Bull. Seism. Soc. Am. 77, 1437-1445.

Bragato, P. L. and Govoni, A., 2000, The Friuli automatic earthquake alert system, Bollettino di Geofisica Teorica ed Applicata 41, 69-77.

Cichowicz, A., 1993, An automatic S-phase picker, Bull. Seism. Soc. Am., 83, 1, 180-189. 
Dai, H. and MacBeth, C., 1997, The application of back-propagation neural network to automatic picking seismic arrivals from single-component recordings, $J$. Geophys. Res., 102, B7, 105-115.

Dowla, F.U., Taylor, S. R. and Anderson, R. W., 1990, Seismic discrimination with artificial neural networks: preliminary results with regional spectral, Bull. Seism. Soc. Am. 80, 1346-1373.

Earle, P. and Shearer, P., 1987, Characterization of global seismograms using an automatic picking algorithm, Bull. Seism. Soc. Am. 84, 2, 366-376.

Gentili, S., 2003a, A New Method For Information Update In Supervised Neural Structures, Neurocomputing, 51C, 61-74.

Gentili, S., 2003b, Retrieving Visual Concepts in Image Databases, Ph.D. Thesis Series, Computer Science 2003/3, Forum eds., Udine, Italy, ISBN 88-8420-152-7.

Gentili, S. and Michelini, A., 2005, Automatic picking of $\mathrm{P}$ and S phases using IUANT2 neural tree, Journal of Seismology (in press).

Lee W. H. K. and Lahr, J. C., 1975, HYPO71 (REVISED) - A computer program for determining hypocenter, magnitude, and first motion pattern of local earthquakes, U.S. Geol. Surv. Open-File Report 75-311, 100 pp.

Leonard, M. and Kennett, B. L. N., 1999, Multi component autoregressive techniques for the analysis of seismograms, Phys. Earth Planet. Int. 113, 2, 247-264.

OGS, 2000-2003, Bollettino della Rete Sismometrica del Friuli-Venezia Giulia e del Veneto. Istituto Nazionale di Oceanografia e di Geofisica Sperimentale - OGS, Dipartimento CentroRicerche Sismologiche, Udine, Italy.

Press, W. H., Teukolsky, S.A., Vetterling, W.T. and Flannery, B.P, 1992, Numerical Recipes in C. The Art of Scientific Computing, Second Edition, 610-612. 
Priolo, E., Barnaba, C., Bernardi, P., Bernardis, G., Bragato, P.L., Bressan, G., Candido, M., Cazzador, E., Di Bartolomeo, P., Durì, G., Gentili, S., Govoni, A., Klinc, P., Kravanja, S., Laurenzano, G., Lovisa, L., Marotta, P., Michelini, A., Ponton, F., Restivo, A., Romanelli, M., Snidarcig, A., Urban, S., Vuan, A. and Zuliani D., 2005, Seismic monitoring in Northeastern Italy: a ten-year experience, Seismological Research Letters, 76, 451-460.

Scherbaum, F. and Johnson, J., 1992, PITSA, Programmable Interactive Toolbox for Seismological Analysis, IASPEI Software Library, Vol. 5. Lee, W. (ed.), 189 pp.

Taylor, J. R., 1982, An Introduction to Error Analysis, The Study of Uncertainties in Physical Measurements, University Science Books.

Wang, J. and Teng, T.L., 1997, Identification and Picking of S Phase Using an Artificial Neural Network, Bull. Seism. Soc. Am. 87, 5, 1140-1149.

Zhang, H., Thurber, C. and Rowe, C., 2003, Automatic P-wave Arrival Detection and Picking with Multiscale Wavelet Analysis for Single-Component Recording, Bull. Seism. Soc. Am. 93, 5, 1904-1912.

Zhao, Y. and Takano, K., 1999, An Artificial Neural Network Approach for Broadband Seismic Phase Picking, Bull. Seismol. Soc. Am. 89, 3, 670-680. 


\section{Figure Captions}

Figure 1. Stations of the Short-period Network of Northeastern Italy and epicenters of the earthquakes considered in this study.

Figure 2. Schematic representation of (a) a perceptron and (b) a multilayer perceptron.

Figure 3. Schematic representation of a simple neural tree involving two perceptrons with two outputs each (on the right) with the enlarged detail on the first perceptron (on the left).

Figure 4. Feature Varrot (equation (5), thick line) and its convolution with the derivative of a Gaussian (feature DVarrot, thin line) computed for two different seismograms in a time window comprising the $\mathrm{P}$ and the $\mathrm{S}$ arrival times. The rough $\mathrm{S}$ pick $S V$, the manual S-pick and $\mathrm{P}$ arrival time are also shown. (a) The horizontal polarization of the $\mathrm{P}$ waves is negligible. (b) The horizontal polarization of the $\mathrm{P}$ waves is significant.

Figure 5. Number and percentage of P picks (gray bars), S picks (black bars) and localized events (white bars) for each database.

Figure 6. Some seismograms from station BAD (central Friuli, see Figure 1) with the indication of the corresponding GB and TAPNEI picks (continuous and dotted vertical lines, respectively). The seismograms are normalized to the maximum amplitude found in any of the three directions. The examples are representative of very good quality automatic S picks $\left(\left|S_{G B}-S_{\text {TAPNEI }}\right|<0.1 s\right)$.

Figure 7. Similar to Figure 6 for $0.1 s<\left|S_{G B}-S_{\text {TAPNEI }}\right|<0.2 s$.

Figure 8. Similar to Figure 6 for $0.2 s<\left|S_{G B}-S_{\text {TAPNEI }}\right|<0.3 s$. 
Figure 9. Similar to Figure 6 for $0.3 s<\left|S_{G B}-S_{\text {TAPNEI }}\right|<0.4 s$.

Figure 10. Similar to Figure 6 for $0.4 s<\left|S_{G B}-S_{\text {TAPNEI }}\right| \leq 0.5 s$. 


\section{Tables Captions}

Table 1. Weighting schema adopted by TAPNEI and based on the S/N ratio computed around the picking point.

Table 2. Comparison between the automatic picks (TAPNEI and FAAS databases) and the corresponding manual ones (GB and OGS databases): $N$ is the number of compared phases; $\mu_{\mathrm{t}}$ and $\sigma_{\mathrm{t}}$ are the mean and standard deviation of the differences in seconds between automatic and manual picks. Precision and Recall are computed according to equations (9) and (10), respectively.

Table 3. Mean $(\mu)$ and standard deviation $(\sigma)$ of the differences in $\mathrm{km}$ between the earthquake locations obtained using TAPNEI and FAAS data and the corresponding ones obtained with manual picks (GB and OGS databases).

Table 4. Absolute standard deviation $\sigma$ of arrival times (in seconds) and hypocentral coordinates (in $\mathrm{km}$ ) of all the analyzed databases. 


\section{Tables}

\begin{tabular}{|c|c|c|c|c|c|}
\hline & $\mathrm{S} / \mathrm{N}<2$ & $2 \leq \mathrm{S} / \mathrm{N}<4$ & $4 \leq \mathrm{S} / \mathrm{N}<6$ & $6 \leq \mathrm{S} / \mathrm{N}<8$ & $\mathrm{~S} / \mathrm{N}>8$ \\
\hline HYPO71 quality class & 4 & 3 & 2 & 1 & 0 \\
\hline
\end{tabular}

Table 1

\begin{tabular}{|c|c|c|c|c|c|}
\hline \multicolumn{2}{|c|}{} & \multicolumn{2}{c|}{ comparison with GB } & \multicolumn{2}{c|}{ comparison with OGS } \\
\hline \multicolumn{2}{|c|}{ phase } & $\mathrm{P}$ & $\mathrm{S}$ & $\mathrm{P}$ & $\mathrm{S}$ \\
\hline \multirow{2}{*}{$\mathrm{N}$} & TAPNEI & 1313 & 950 & 6278 & 3976 \\
\cline { 2 - 6 } & FAAS & 1101 & 489 & 4728 & 1672 \\
\hline \multirow{2}{*}{$\mu_{\mathrm{t}} \pm \sigma_{\mathrm{t}}(\mathrm{s})$} & TAPNEI & $0.00 \pm 0.07$ & $0.00 \pm 0.18$ & $0.00 \pm 0.07$ & $0.06 \pm 018$ \\
\cline { 2 - 7 } & FAAS & $-0.02 \pm 0.07$ & $0.14 \pm 0.21$ & $-0.03 \pm 0.07$ & $0.14 \pm 0.25$ \\
\hline \multirow{2}{*}{ Precision } & TAPNEI & 0.92 & 0.98 & 0.90 & 0.95 \\
\cline { 2 - 6 } & FAAS & 0.99 & 0.98 & 0.91 & 0.97 \\
\hline \multirow{2}{*}{ Recall } & TAPNEI & 0.93 & 0.84 & 0.80 & 0.76 \\
\cline { 2 - 6 } & FAAS & 0.80 & 0.43 & 0.62 & 0.30 \\
\hline
\end{tabular}

Table 2

\begin{tabular}{|c|c|c|c|c|c|c|c|}
\hline \multicolumn{2}{|c|}{} & \multicolumn{3}{|c|}{ comparison with GB } & \multicolumn{3}{c|}{ comparison with OGS } \\
\hline \multicolumn{2}{|c|}{ component } & $\Delta \mathrm{X}$ & $\Delta \mathrm{Y}$ & $\Delta \mathrm{Z}$ & $\Delta \mathrm{X}$ & $\Delta \mathrm{Y}$ & $\Delta \mathrm{Z}$ \\
\hline \multirow{2}{*}{$\mu \pm \sigma(\mathrm{km})$} & TAPNEI & $-0.18 \pm 0.77$ & $0.10 \pm 0.62$ & $0.1 \pm 2.0$ & $0.00 \pm 0.84$ & $0.00 \pm 0.79$ & $-0.8 \pm 2.3$ \\
\cline { 2 - 7 } & FAAS & $-0.34 \pm 0.93$ & $0.24 \pm 0.69$ & $1.0 \pm 2.6$ & $-0.16 \pm 1.13$ & $-0.01 \pm 0.89$ & $2.5 \pm 3.3$ \\
\hline
\end{tabular}

Table 3 


\begin{tabular}{|c|c|c|c|c|c|}
\hline database & $\sigma \mathrm{P}(\mathrm{s})$ & $\sigma \mathrm{S}(\mathrm{s})$ & $\sigma \mathrm{X}(\mathrm{km})$ & $\sigma \mathrm{Y}(\mathrm{km})$ & $\sigma \mathrm{Z}(\mathrm{km})$ \\
\hline GB & 0.03 & 0.07 & 0.2 & 0.0 & 0.0 \\
\hline OGS & 0.03 & 0.12 & 0.6 & 0.5 & 1.4 \\
\hline FAAS & 0.06 & 0.18 & 0.9 & 0.7 & 2.9 \\
\hline TAPNEI & 0.06 & 0.18 & 0.7 & 0.6 & 2.1 \\
\hline
\end{tabular}

Table 4 
Figure

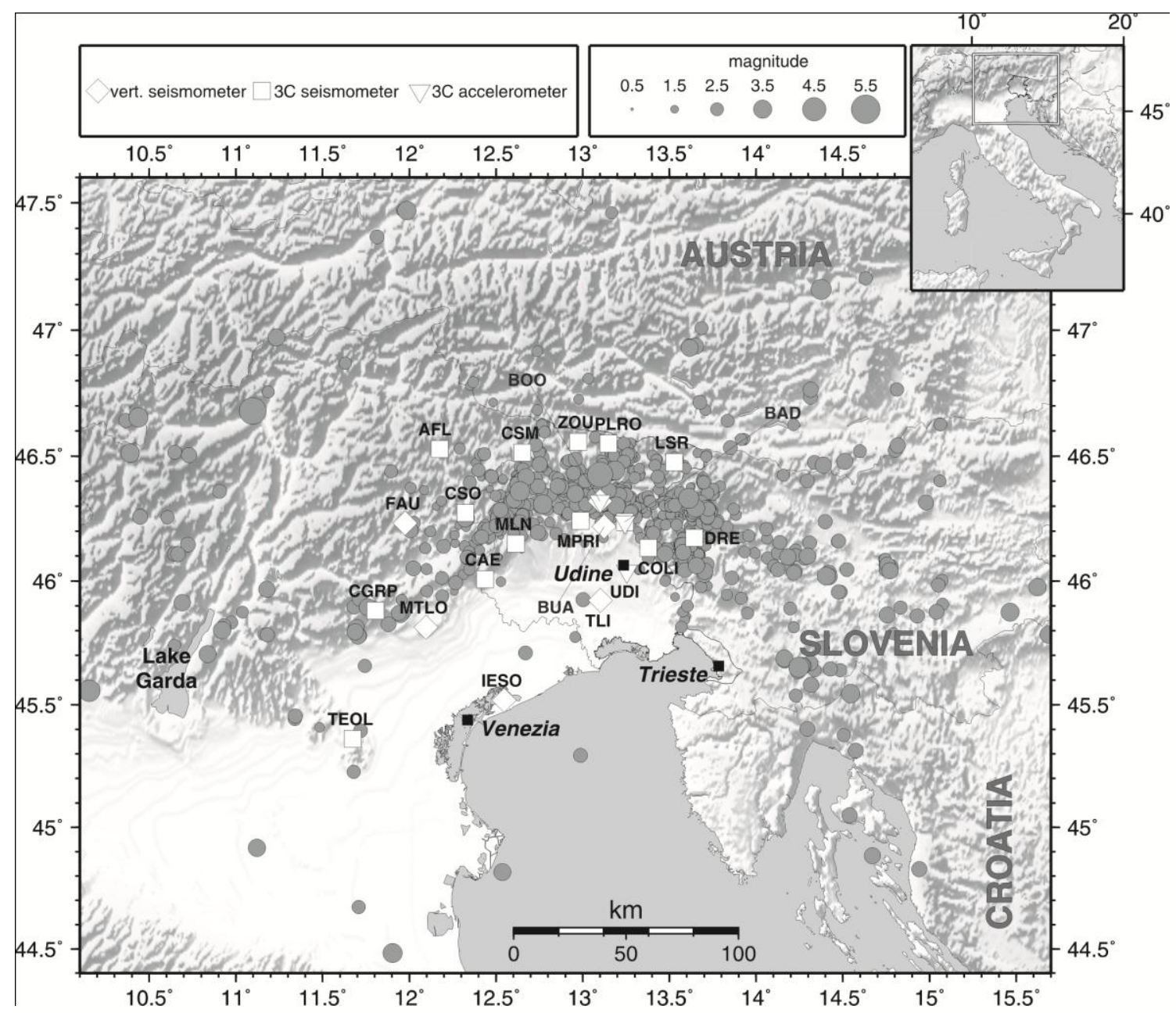

Fig. 1
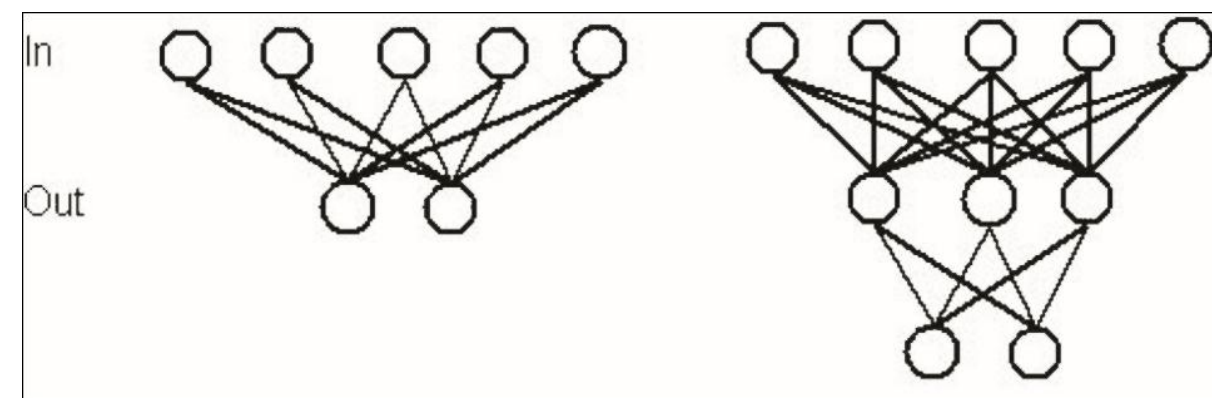

in

Hidden

Fig. 2

Out 


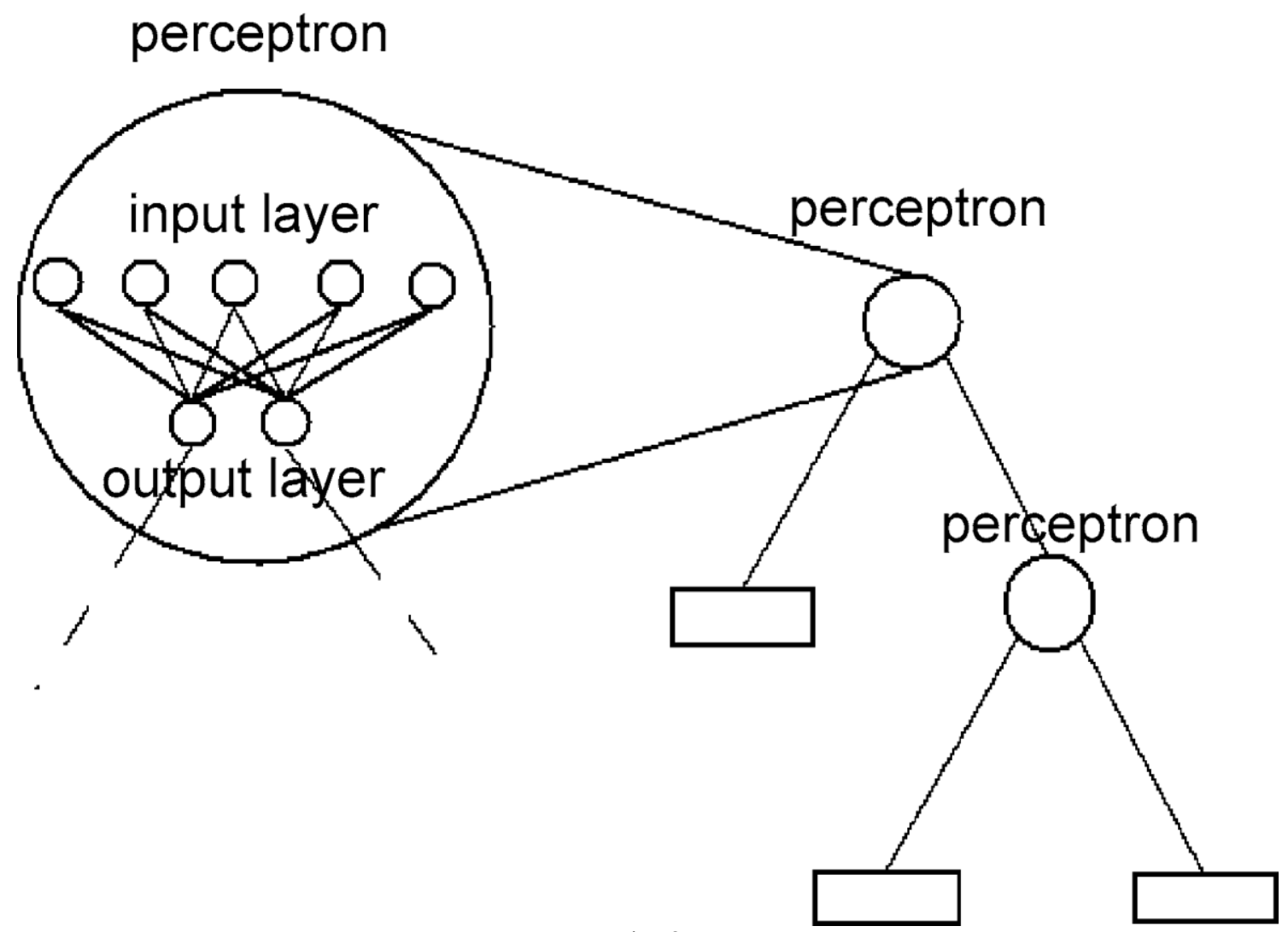

Fig. 3 


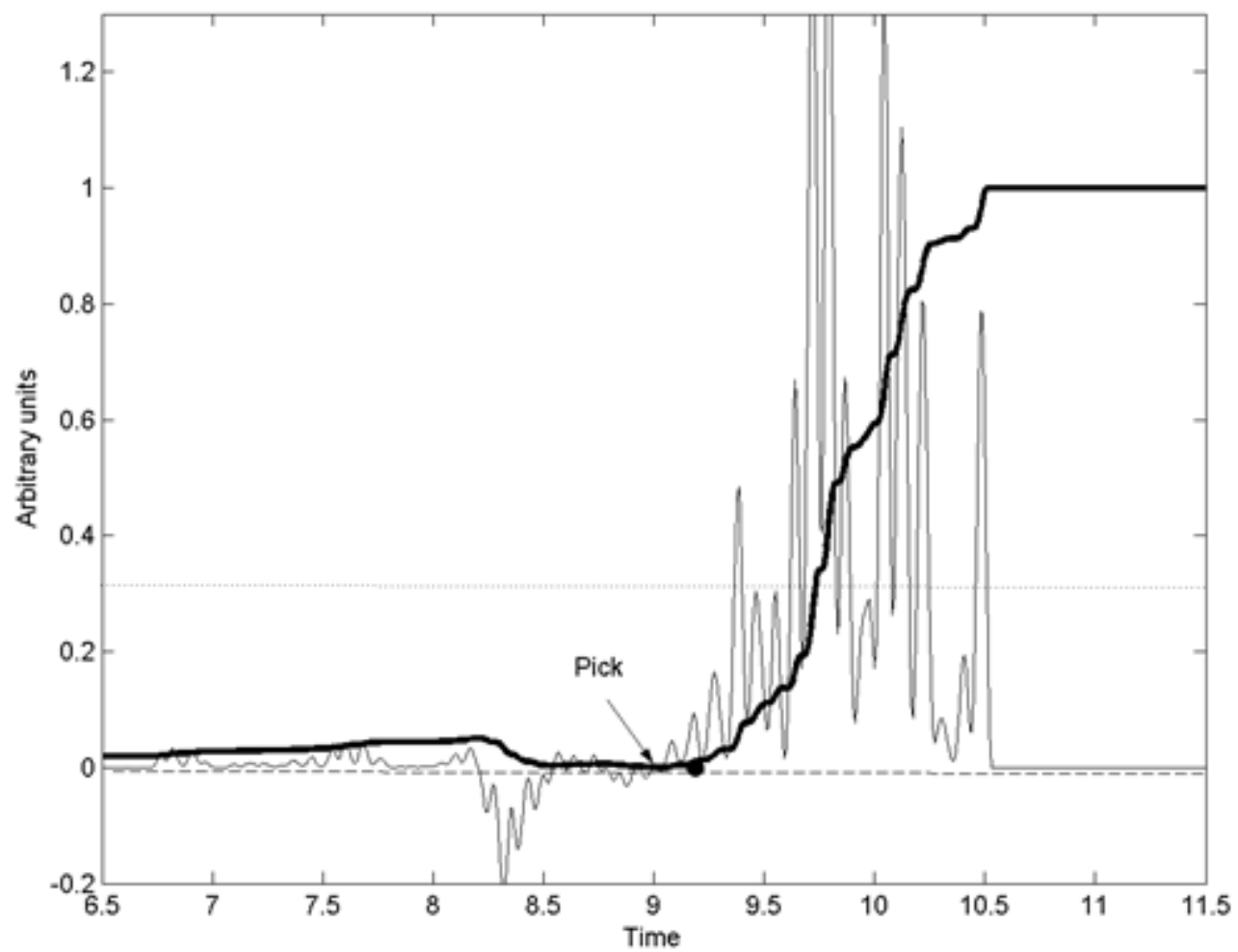

(a)

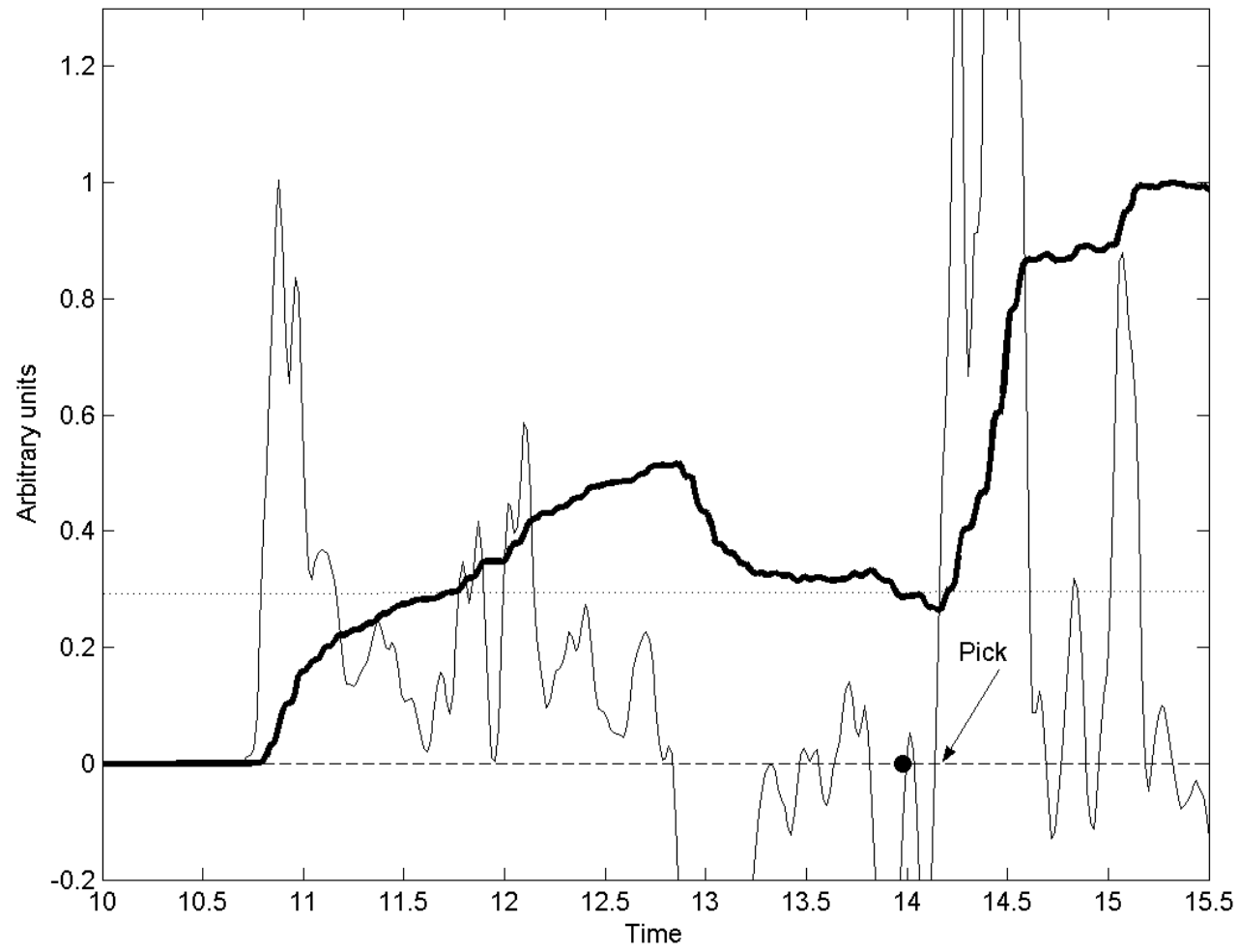

Fig. 4 


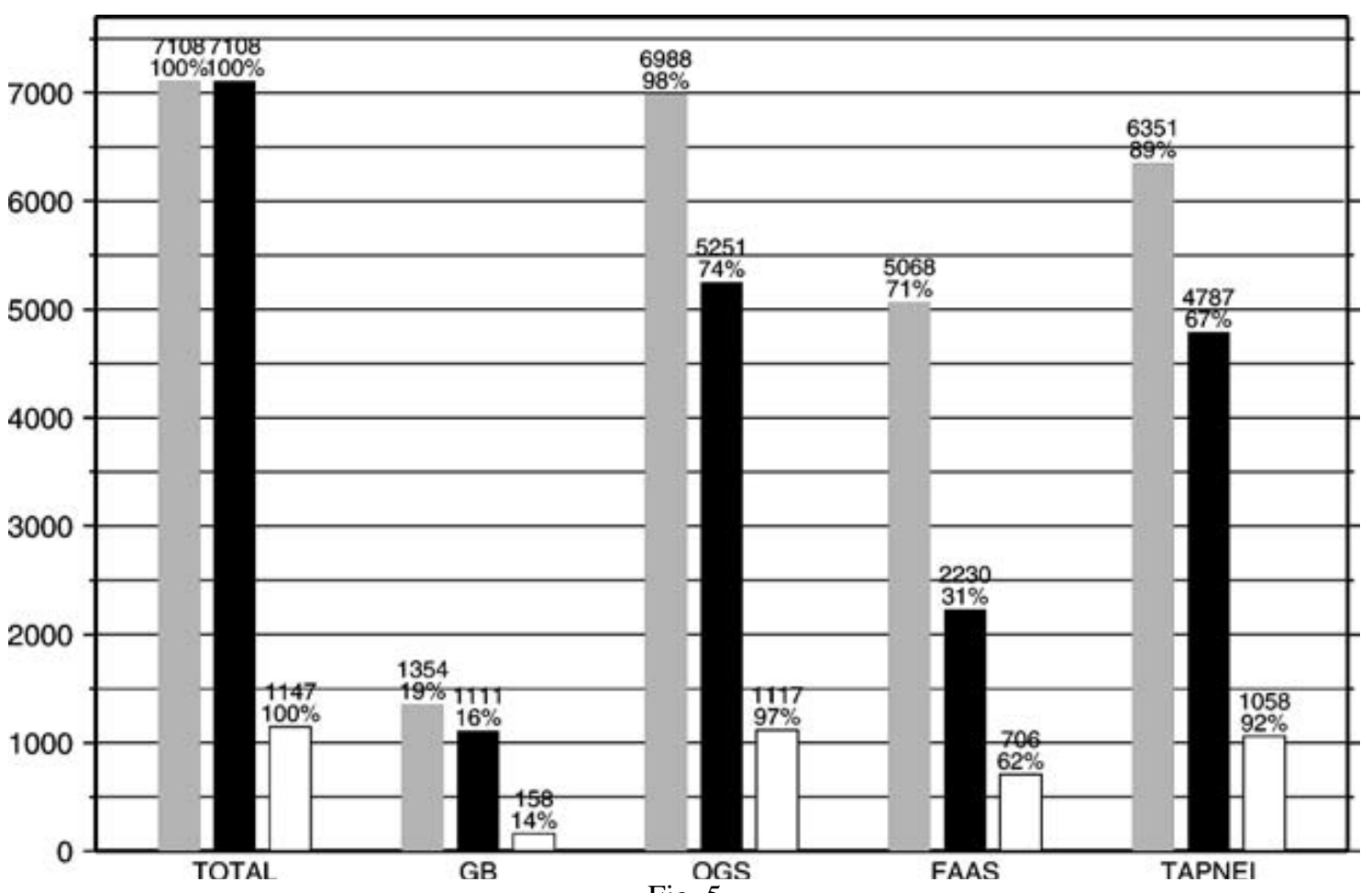

Fig. 5 

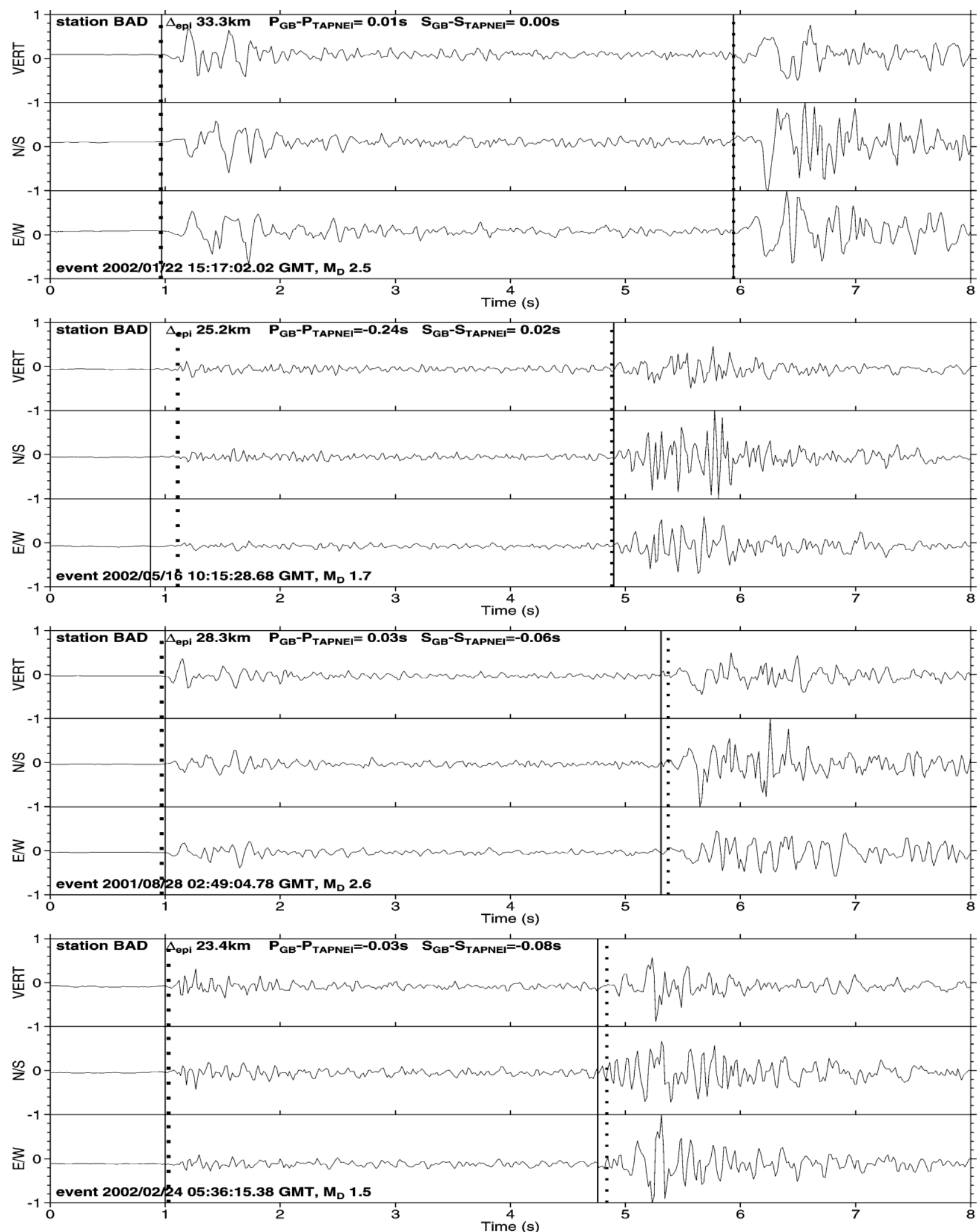

Fig. 6 

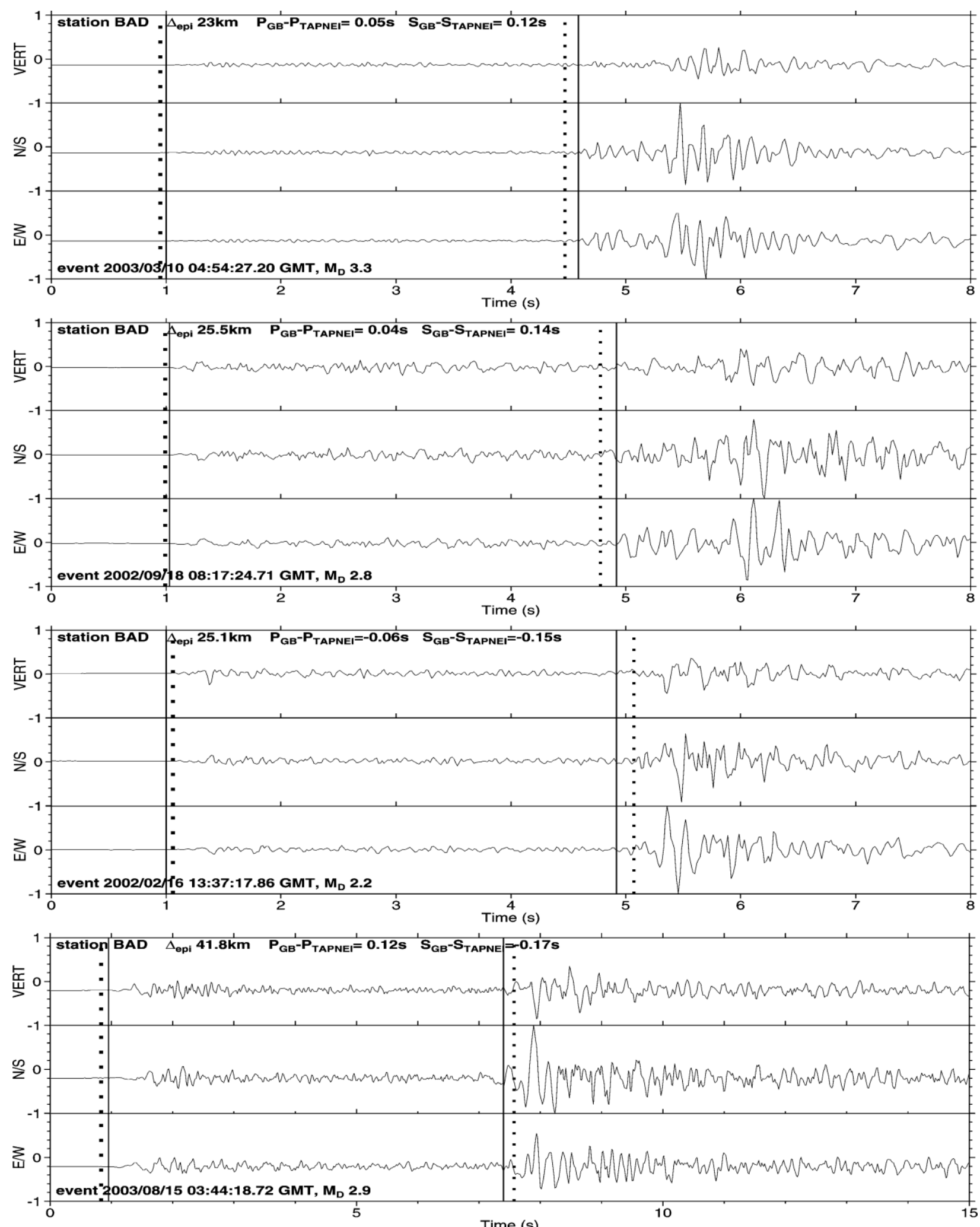

Fig. 7 

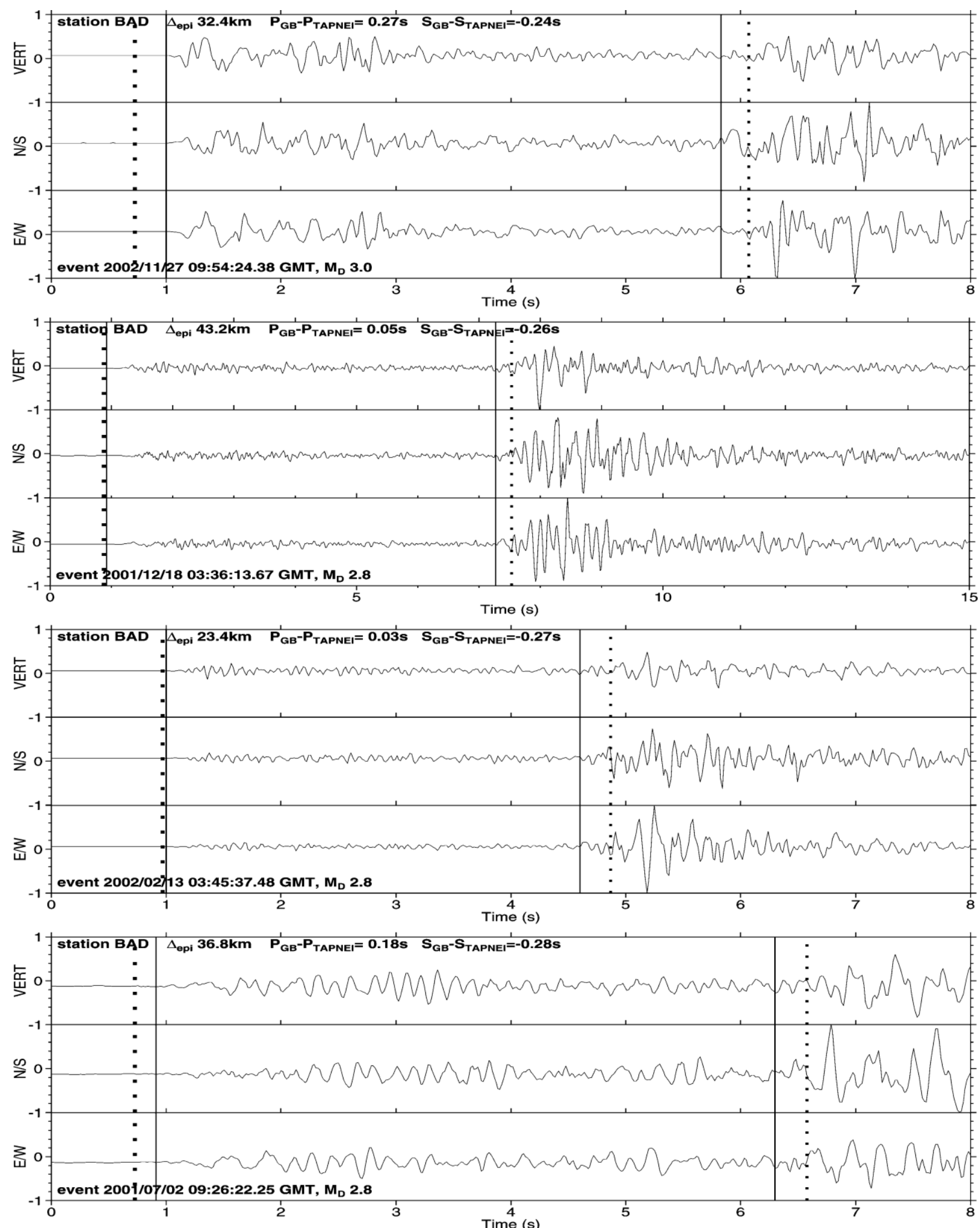

Fig. 8 

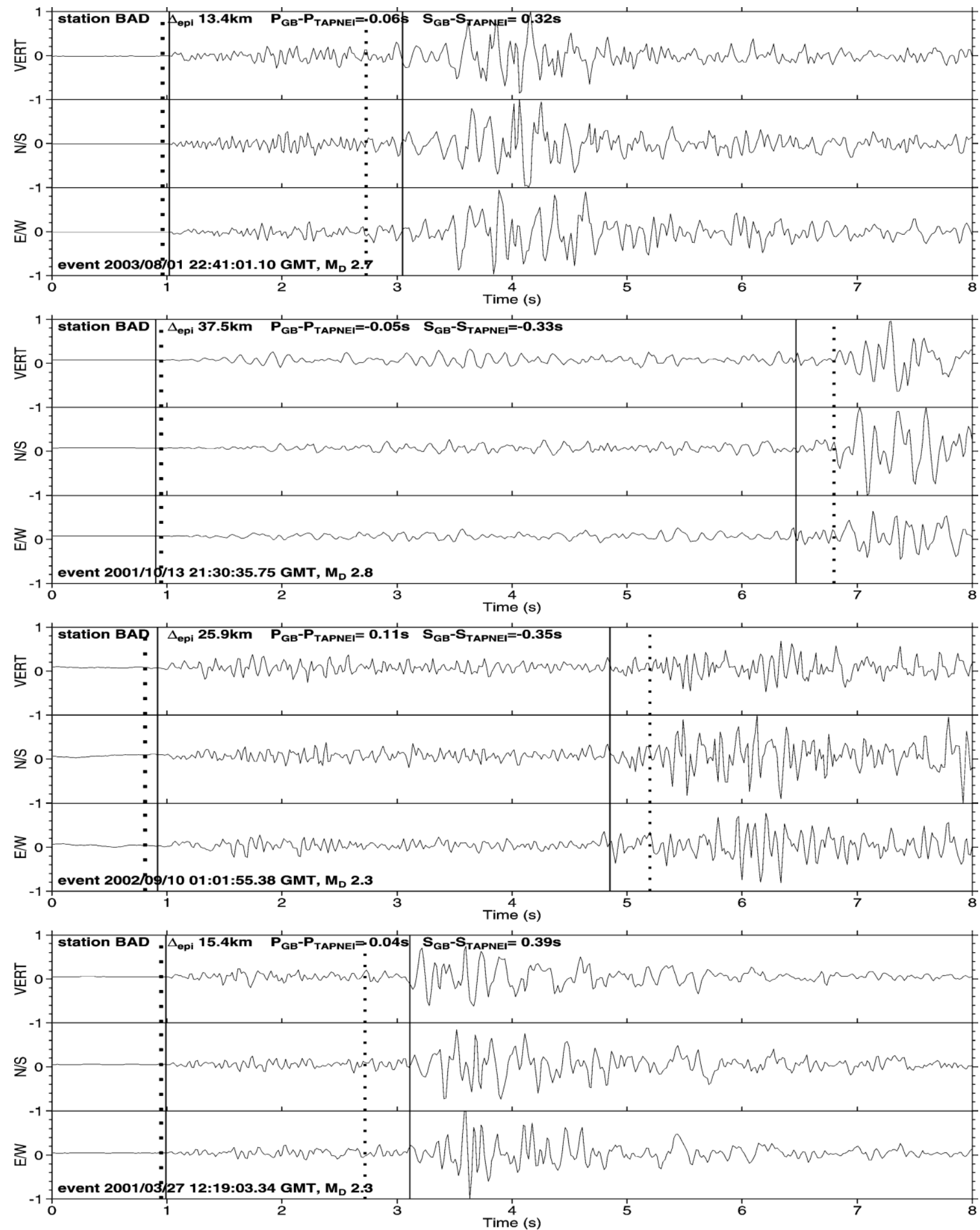

Fig. 9 

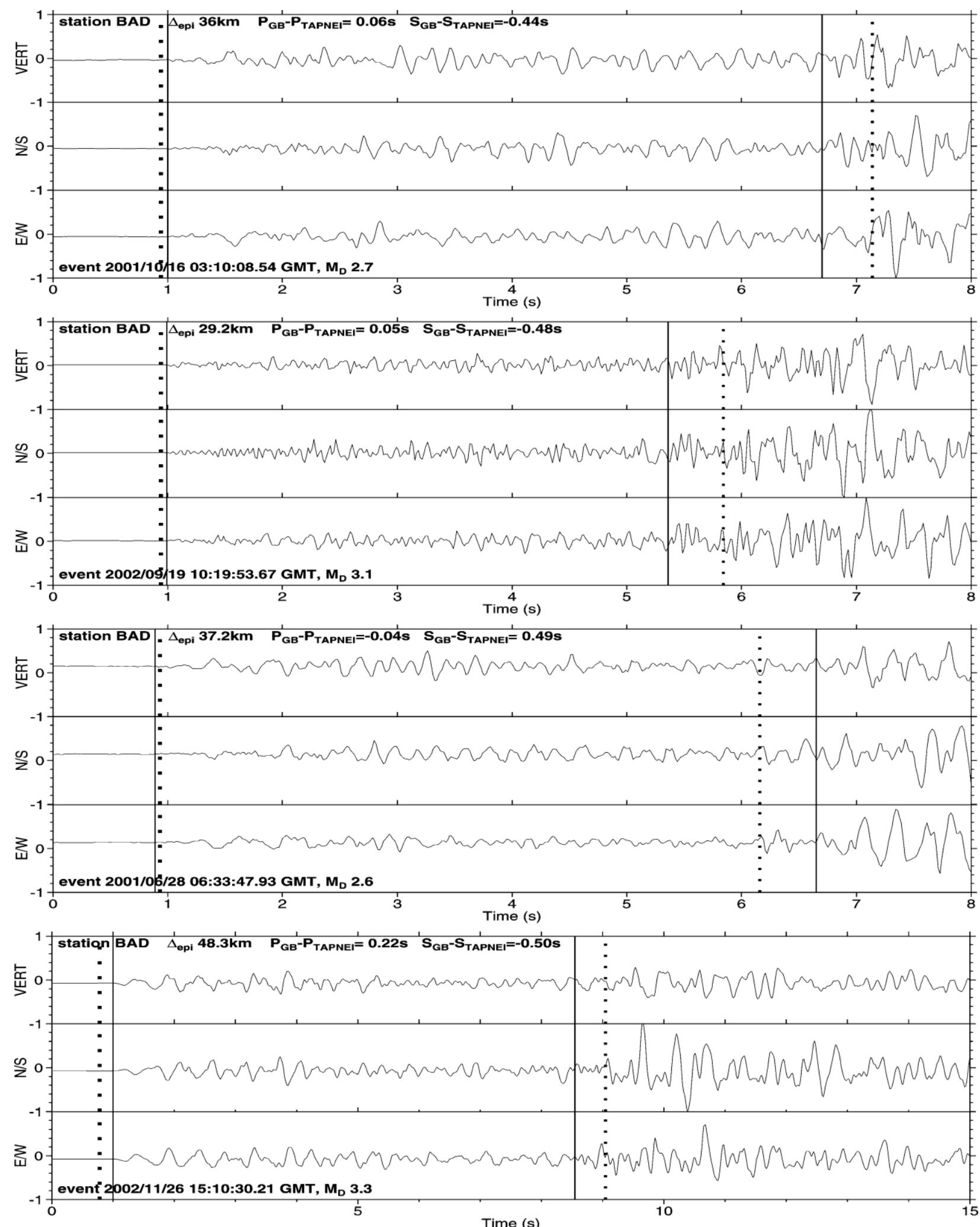

Fig. 10 